\title{
Life Cycle Assessment of Methyl Bromide Production and Utilization: Cradle to Grave Analysis
}

Sampatrao Manjare ( $\nabla$ manjare@goa.bits-pilani.ac.in )

BITS Pilani K K Birla Goa Campus Goa https://orcid.org/0000-0002-9770-3145

Amit Shanbag

Goa State Pollution Control Board

Research

Keywords: cradle to gate, cradle to grave, environmental impacts, life cycle assessment, methyl bromide

Posted Date: June 16th, 2021

DOI: https://doi.org/10.21203/rs.3.rs-605031/v1

License: (9) This work is licensed under a Creative Commons Attribution 4.0 International License.

Read Full License 


\title{
Life Cycle Assessment of Methyl B romide Production and Utilization: Cradle to Grave Analysis
}

\author{
Sampatrao Manjare**1, Amit Shanbag ${ }^{2}$ \\ ${ }^{1}$ BITS Pilani K K Birla Goa Campus Goa, 403726 India \\ ${ }^{2}$ Goa State Pollution Control Board, Goa 403001, India \\ *Email of Corresponding Author: manjare@goa.bits-pilani.ac.in
}

\begin{abstract}
Methyl bromide is an effective and useful insecticide. It has ability to enter rapidly into materials at room temperature \& pressure. Nowadays, it is primarily used for container fumigation purposes. However, exposure to it causes serious health-related issues. It is also one of the ozone-depleting substances. In this work, "cradle to gate" and "cradle to grave" approaches are considered to carry out a life cycle assessment of methyl bromide production. SimaPro software with the IMPACT 2002+ method is used to compute the results. From the results of cradle to gate approach, it is inferred that major emissions are due to usage of plant utilities and methanol production process which have a substantial effect on the atmosphere. From the results of cradle to grave approach, it is noted that application of methyl bromide causes significant environmental damage particularly to ozone layer followed by non-carcinogen.
\end{abstract}

Keywords: cradle to gate; cradle to grave; environmental impacts; life cycle assessment; methyl bromide

\section{Introduction}

Methyl bromide(MB) is a fumigant primarily applied to control weeds, pathogens, pests, nematodes, and rodents. ${ }^{1}$ Previously the principal use of MB was for the fumigation of the agricultural soil and storage areas susceptible to pests. ${ }^{2,3}$ The application of MB (gas at temperatures above $4^{\circ} \mathrm{C}$ ) as a soil fumigant results 
in almost complete eradication of populations of a wide variety of microflora and fauna, as well as other soil organisms. ${ }^{4}$

It has been studied that MB predominantly effects on ozone layer depletion. ${ }^{5,6}$ The amount of MB produced has been regulated because of its potential to cause ozone layer depletion. Countries such as the United States have completely phased it out since 2005 in compliance with the Montreal Protocol on constituents that result in ozone layer depletion (OLD) and also under the Clean Air Act (CAA). ${ }^{7}$ However, MB is presently used under tight controls especially for container fumigation purposes. Its density is 3 times higher than air due to which it settles down in areas having low ventilation. ${ }^{8}$ However, MB is approved fumigant for wooden packaging materials or pallets. ${ }^{9}$ The total global production of MB was 13553 tonnes in 2017 including the 3,093 tonnes for laboratory and analytical uses (United Nations Environment Programme 2018). ${ }^{10}$

Some researchers have found out that MB is harmful since it causes site destruction in cells of an organism. ${ }^{11,12}$ Researchers in their study have found evidence that MB causes genetic changes. ${ }^{13}$ The U.S. EPA classifies MB as a group D carcinogen as there is no adequate data for humans and animals which determines whether it causes cancer. ${ }^{14}$

Generally, the atmospheric concentration of MB is approximately $<0.025 \mathrm{ppb}$ and in industrial areas, it is around $1.2 \mathrm{ppb}$. If proper personal protective types of equipment are not used, workers who are in direct contact with MB can be affected by high levels of MB. MB is naturally produced by algae or kelp in oceans. ${ }^{15}$ The probability of groundwater contamination is very less as MB gets dispersed in the atmosphere during its application, however, the presence of MB have been noticed in drinking water. ${ }^{16}$

MB is highly toxic. It affects the lungs and neurological system in humans. ${ }^{15}$ The typical symptoms of MB inhalation are dizziness, headache, convulsions, difficulty in breathing, speech impairment, and body in-coordination. When exposed to skin it can result in itching and tingling while on being absorbed by the skin redness, pain and burning sensation with blisters can occur. Exposure to the eyes can result in blurred vision and temporary loss of sight. It is also classified as an endocrine-disrupting agent. ${ }^{17}$ 
MB toxicity has not been adequately characterized and there is very little research in areas like dietary exposure, applicator exposure, and groundwater contamination. ${ }^{18}$ In a study of human mortality, people exposed to MB were found to have testicular cancer but it could not be proved since the people were also exposed to brominated chemicals. ${ }^{1,15,17}$ A study carried out suggests that exposure to MB through inhalation my result in minor mutilation of the nervous system of human beings. However, this does not consider exposure to other substances simultaneously and insufficient evaluation of concentrations and periods. ${ }^{1,15,17}$ Neurological effects are observed in the animal study, effects such as lethargy, forelimb twitching, tremors, and paralysis. ${ }^{17}$ Exposure to high dosages may lead to death through lung injury along with cardiac failure. ${ }^{19}$ The latent period is in the range of between 0.5 to 48 hours and varies from person to person. ${ }^{20}$ When human skin comes in contact with higher concentrations or with liquid MB, it may lead to extreme burns. $^{21}$

As mentioned above, $\mathrm{MB}$ is highly toxic to humans as well as animals. Being mostly used for fumigation purposes, it is easily dispersed into the air which leads to ozone layer depletion. One of the raw materials essential for the manufacture of $\mathrm{MB}$ is bromine, which is also highly toxic which can cause chemical burns in human flesh when in contact and irritation of the respiratory tract when inhaled. MB has a tropospheric mixing ratio $12 \mathrm{pptv}, 0.7 \mathrm{yrs}$ atmospheric lifetime, and 0.51 ozone-depleting potential. When fumigated, this MB releases bromine when it is exposed to UV light in the stratosphere as shown in reaction 1 (EPA- Basic Ozone layer science). The primary source of stratospheric bromine is MB which is produced biogenically in the ocean and emitted as soil fumigant. ${ }^{22,23}$

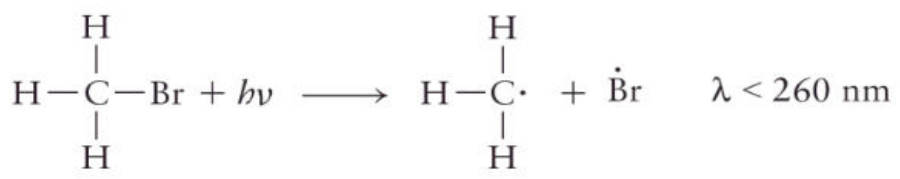

Once the atomic bromine is released, bromine catalytic ozone destruction gets started as shown in reaction 2. 


$$
\begin{gathered}
\dot{\mathrm{Br}}+\mathrm{O}_{3} \longrightarrow \mathrm{BrO}+\mathrm{O}_{2} \\
\frac{\mathrm{BrO}+\dot{\mathrm{O}} \cdot \longrightarrow \dot{\mathrm{Br}}+\mathrm{O}_{2}}{\dot{\mathrm{O}} \cdot+\mathrm{O}_{3} \longrightarrow 2 \mathrm{O}_{2} \quad \text { (net process) }}
\end{gathered}
$$

Micro-organisms and water also break down MB. ${ }^{24,25}$ From the above discussion, it is clear that the evaluation of environmental effects related to the production process of $\mathrm{MB}$ is required. This will help in planning to minimize these effects by way of source reduction and control. Life Cycle Assessment (LCA) is a tool to estimate the environmental impacts associated with any service/product or process over its entire life cycle right from the extraction of the raw material, to its use and finally its eventual disposal..$^{25,26}$

There are no research details available on the LCA study of the production process of MB. However, the environmental impact associated with the application of MB as a fumigant has been compared with other pest treatment methods viz., wooden pallets including conventional Heat Treatment (HT), and Microwave induced Heat Treatment (MW). ${ }^{7}$ The results of this study revealed that among the three treatment methods, MB has a greater impact on global warming (GW) and OLD. However, the detailed environmental impact assessment for the MB production process is necessary. In this work environmental impacts associated with the production of MB have been estimated using LCA.

\section{Methyl Bromide Process Description}

There are for main stages to produce MB

- Reaction

- Purification

- Condensation

- $\quad$ Storage and packaging

\subsection{Reaction}

The raw materials required for the reaction are methanol, hydrogen bromide and sulfuric acid in which methanol converts into MB:

$$
\mathrm{CH}_{3} \mathrm{OH}+\mathrm{H}_{3} \mathrm{O}^{+}+\mathrm{Br}^{-} \stackrel{\text { ConcH2SO4}}{\longrightarrow} \mathrm{CH}_{3} \mathrm{Br}+2 \mathrm{H}_{2} \mathrm{O}
$$


The reactor should be cooled since the reaction is exothermic. Hydrogen bromide supply is controlled by bromine by the reaction of bromine and sulfur as shown below:

$$
3 \mathrm{Br}_{2}+\frac{1}{8} \mathrm{~S}_{8}+11 \mathrm{H}_{2} \mathrm{O} \rightarrow 7 \mathrm{H}_{3} \mathrm{O}^{+}+6 \mathrm{Br}^{-}+\mathrm{HSO}_{4}^{-}
$$

The by-product of this reaction is sulphuric acid. The reactants do not get converted and by-products are also formed. Hence MB needs to be purified.

\subsection{Purification}

The crude MB is purified by various steps like washings, distillations, and extractions. After the treatment, hydrogen bromide and bromine traces are removed but also generate water vapors. To remove this water and dry the product, sulfuric acid is used. The sulfuric acid is then transferred to the distillation tower. The un-reacted reactants are recycled to the reactor and $\mathrm{MB}$ and sulfuric acid are obtained as product and byproduct respectively.

$$
\begin{gathered}
\mathrm{HBr}+\mathrm{OH}^{-} \rightarrow \mathrm{Br}^{-}+\mathrm{H}_{2} \mathrm{O} \\
3 \mathrm{Br}_{2}+6 \mathrm{OH}^{-} \rightarrow 5 \mathrm{Br}^{-}+\mathrm{BrO}_{3}^{-}+3 \mathrm{H}_{2} \mathrm{O}
\end{gathered}
$$

\subsection{Condensation}

The pure MB obtained from the purification is then condensed and stored. Condensation takes place into two steps. First it is cooled with a brine solution to $-20^{\circ} \mathrm{C}$ and then by ammonia to $-40^{\circ} \mathrm{C}$. Hence $\mathrm{MB}$ gas liquefies with very low vapor pressure. To trap the uncondensed gas, a deep cooling system with an absorption column is attached. It prevents the gas from any leakage.

\subsection{Storage and packaging}

Condensed MB is stored in double-walled storage tanks. Before shipping, it is kept in ISO tanks and containers which can resist the pressure of $15 \mathrm{~atm}$ but to be on the safer side it is filled at 6atm pressure.

Detailed data with regards to the raw materials, utility requirements, products, emissions, and effluent, has been provided by Intech Organics Ltd for this study. 


\section{Life Cycle Assessment}

Nowadays, resource and environmental problems linked to industrial growth have become progressively more obvious. Many businesses have realized that it is imperative to look at ways of using various approaches for the reduction in pollution at the source and environmental management systems to improve their environmental performance. LCA is such a tool for quantifying the environmental impact along with the product entire life cycle. ${ }^{26}$

LCA is a scientific assessment technique to encourage resource-saving and environmental protecting behavior and could provide a better understanding of potential environmental impact for the decision-making process. ${ }^{27}$ Therefore these days, LCA has become one of the most accepted and used tools for the environmental assessment of products and services. ${ }^{28}$ This paper presents LCA study on MB production using a cradle-tograve approach and results have been compared with cradle to gate approach so that environmental impacts due to the application of the product are also understood. This would help decision-makers in taking appropriate decisions regarding the preventive steps to reduce the overall impact of product development.

\section{Life Cycle Assessment Methodology}

The LCA consists of four steps: goal definition and scoping, inventory analysis, impact assessment, and interpretation ${ }^{29,30}$ and are explained in the following section.

\subsection{Goal and scope definition}

The goal of this study was to estimate environmental impacts associated with the MB production facility located at Intech Organics Ltd(formerly known as Intech Pharma Pvt. Ltd), Dhargal Goa, India. Two approaches viz. cradle to gate (CTGT), and cradle to grave (CTGR) have been used to carry out LCA of MB production. The LCA system boundaries, for the MB production process, using CTGT and CTGR are presented in Fig 1 (a) and Fig. 1(b) respectively. 


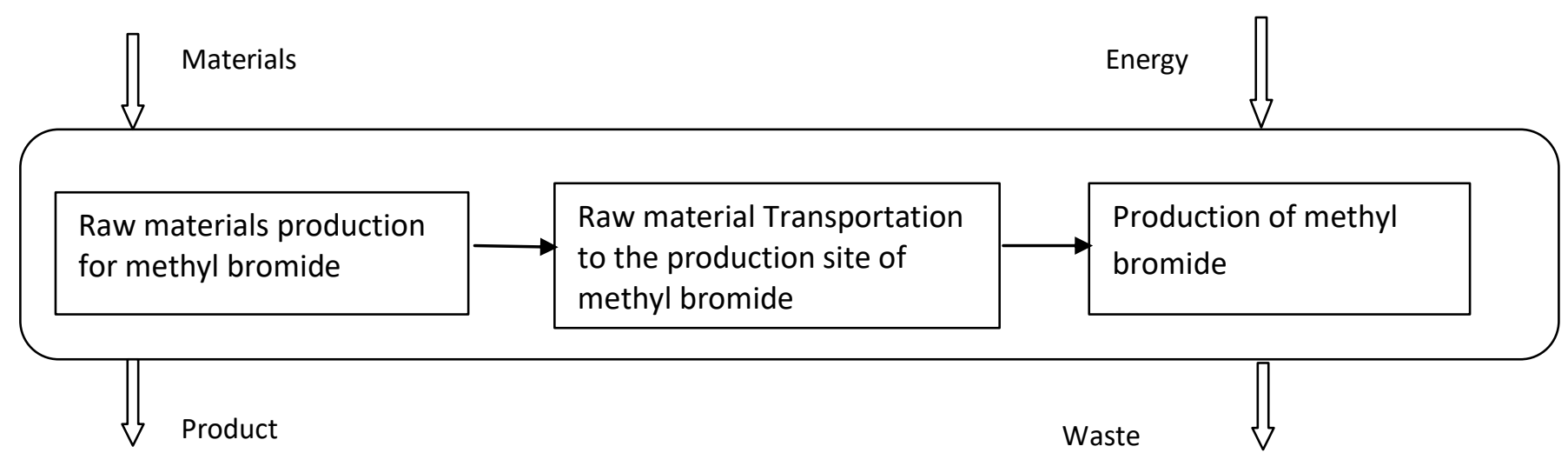

Fig 1(a): Stages in the life cycle of a methyl bromide production (LCA system bounuary) Ior cradle to gate (CTGT) approach

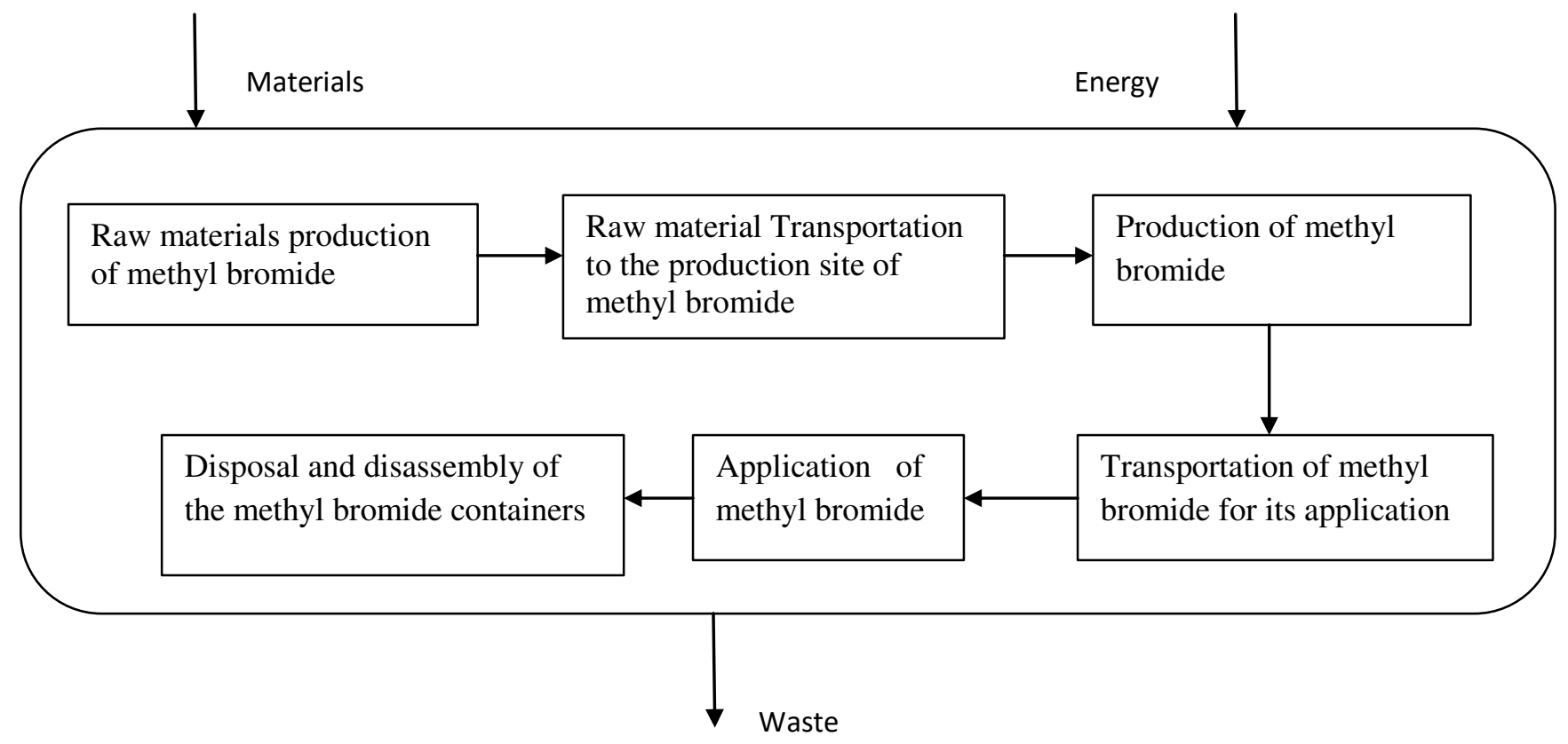

Fig. 1(b): Stages in the life cycle of a methyl bromide production (LCA system boundary) for cradle to grave (CTGR) approach

\section{Functional Unit}

For this study functional unit of $1 \mathrm{~kg}, \mathrm{MB}$ manufactured, packaged, transported, and used is considered.

\subsection{Life cycle inventory analysis}


The block diagram of the MB production process is shown in Fig. 2. The reaction scheme is shown in reaction 3.

$$
6 \mathrm{CH}_{3} \mathrm{OH}+3 \mathrm{Br}_{2}+\mathrm{S} \rightarrow 6 \mathrm{CH}_{3} \mathrm{Br}+\mathrm{H}_{2} \mathrm{SO}_{4}+2 \mathrm{H}_{2} \mathrm{O} \ldots . .(3)
$$

Inventory data for production of $1 \mathrm{~kg}$ of MB is given in Table 1 . Table 1 also includes data for raw material transportation, energy requirements, product packaging materials, and emissions. Transport, application, emissions of MB, and disposal of materials used to contain MB are given in Table 2. 


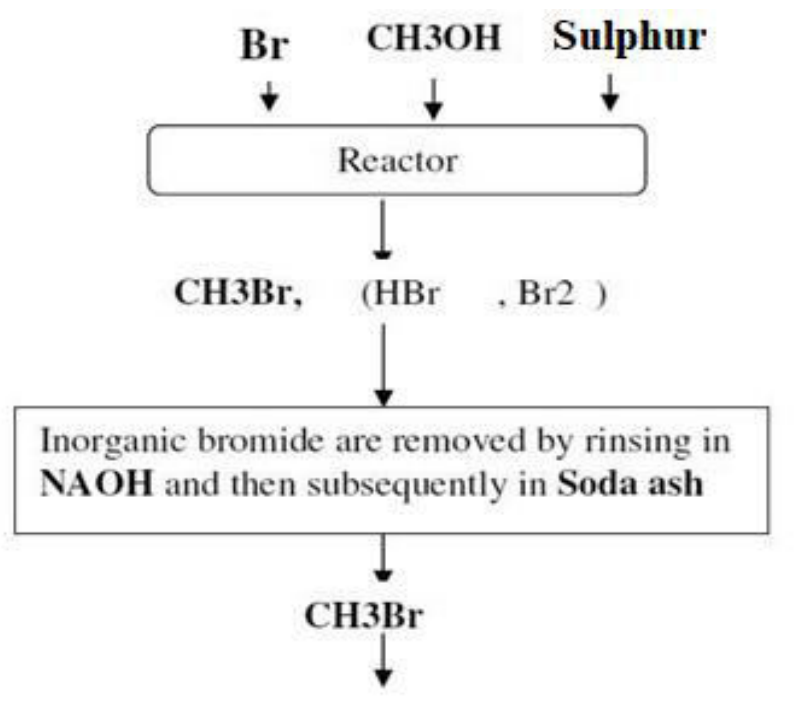

Drying of the product by sulfuric acid

\section{$\mathrm{CH}_{3} \mathrm{Br}$}

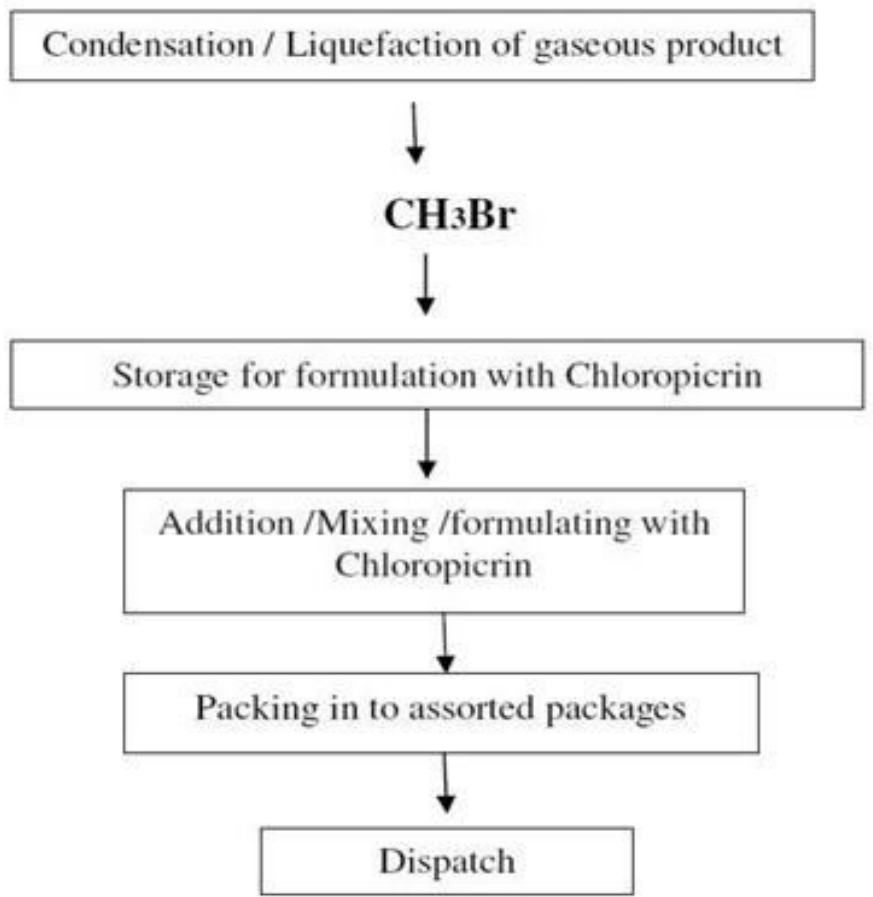

Fig.2 Block diagram for MB production 
Table 1. Inventory data for production of $1 \mathrm{~kg}$ of MB

\begin{tabular}{|c|c|c|}
\hline Input/output material and energy & Quantity & Unit \\
\hline \multicolumn{3}{|l|}{ Raw Materials } \\
\hline Methanol & 0.387 & $\mathrm{~kg}$ \\
\hline Bromine & 0.672 & $\mathrm{~kg}$ \\
\hline Sulfur & 0.062 & $\mathrm{~kg}$ \\
\hline Sulphuric Acid & 0.132 & $\mathrm{~kg}$ \\
\hline Sodium Carbonate & 0.005 & $\mathrm{~kg}$ \\
\hline Sodium Hydroxide & 0.005 & $\mathrm{~kg}$ \\
\hline Water & 0.1588 & $\mathrm{~kg}$ \\
\hline \multicolumn{3}{|l|}{ Transport of raw materials } \\
\hline Roadways: Diesel truck & 500 & kgkm \\
\hline \multicolumn{3}{|l|}{ Energy Inputs } \\
\hline Electricity & 0.73 & $\mathrm{kWh}$ \\
\hline Steam & 0.756 & $\mathrm{~kg}$ \\
\hline High-Speed Diesel & 0.0254 & $\mathrm{~kg}$ \\
\hline \multicolumn{3}{|l|}{ Emissions } \\
\hline Particulate Matter & 0.077 & $\mathrm{~g}$ \\
\hline Sulfur dioxide & 0.311 & $\mathrm{~g}$ \\
\hline Nitrogen oxides & 0.006 & $\mathrm{~g}$ \\
\hline Carbon monoxides & 0.005 & $\mathrm{~g}$ \\
\hline Hydrocarbons & 0.006 & $\mathrm{~g}$ \\
\hline COD & 0.0156 & $\mathrm{mg}$ \\
\hline Suspended Solids & 0.012 & $\mathrm{mg}$ \\
\hline Oil and grease & 0.008 & $\mathrm{mg}$ \\
\hline \multicolumn{3}{|l|}{ Packaging of $M B$} \\
\hline Cylinders & 0.36 & $\mathrm{~kg}$ \\
\hline Cans & 0.03 & $\mathrm{~kg}$ \\
\hline
\end{tabular}


Table 2 Inventory data for transport, application, and emissions of MB during the application and disposal of materials used to keep MB

\begin{tabular}{|l|c|c|}
\hline Input/output & Quantity & Unit \\
\hline Transport of product & 500 & $\mathrm{kgkm}$ \\
\hline Roadways: Diesel truck & 1 & $\mathrm{~kg}$ \\
\hline Application & \multicolumn{3}{|c|}{} \\
\hline MB & 0.87 & $\mathrm{~kg}$ \\
\hline Air emission & & $\mathrm{kg}$ \\
\hline MB & 0.36 & $\mathrm{~kg}$ \\
\hline Recycling of packaging material & 0.03 & \\
\hline Steel and iron cylinder & & \\
\hline Aluminum can &
\end{tabular}

\subsection{Life cycle impact assessment}

Life Cycle Impact Assessment (LCIA) is carried out using SimaPro software. For this study IMPACT, 2002+ method is considered. This method proposes a possible execution of a combined midpoint approach, connecting all types of life cycle inventory results via 15 midpoint categories to four damage categories (ILCD, 2010; Eco-indicator 99 and CML 2002). Normalization can be performed either at the midpoint or at damage level (Jolliet et al. 2003). For this study, normalization is performed at the midpoint level.

\section{Results and Discussion}

\subsection{Cradle to gate approach}

The LCA study of the MB production process is carried out using the CTGT approach. In this approach, raw materials production processes along with the production process of $\mathrm{MB}$ are considered. Transportation of raw materials and packaging of the product are also considered for the CTGT analysis.

The LCA results, obtained using this approach, are presented through Fig.3-4. The characterization of emissions in the production process of MB is shown in Fig. 3. From Fig. 3 it is observed that the methanol production process, electricity use, diesel combustion, and onsite steam production have a significant environmental impact as compared to the MB production process. The various environmental attributes 
affected are also indicated in Fig.3. It is also observed that the production process of sulfur and the transportation of raw materials have a notable impact on various impact categories. However, the production process of $\mathrm{MB}$ has a minor impact on only respiratory inorganics, terrestrial and aquatic acidification, aquatic eutrophication, and global warming. From these results, it is revealed that the production of raw materials and energy causes significant environmental impact as compared to the production process of methyl bromide.

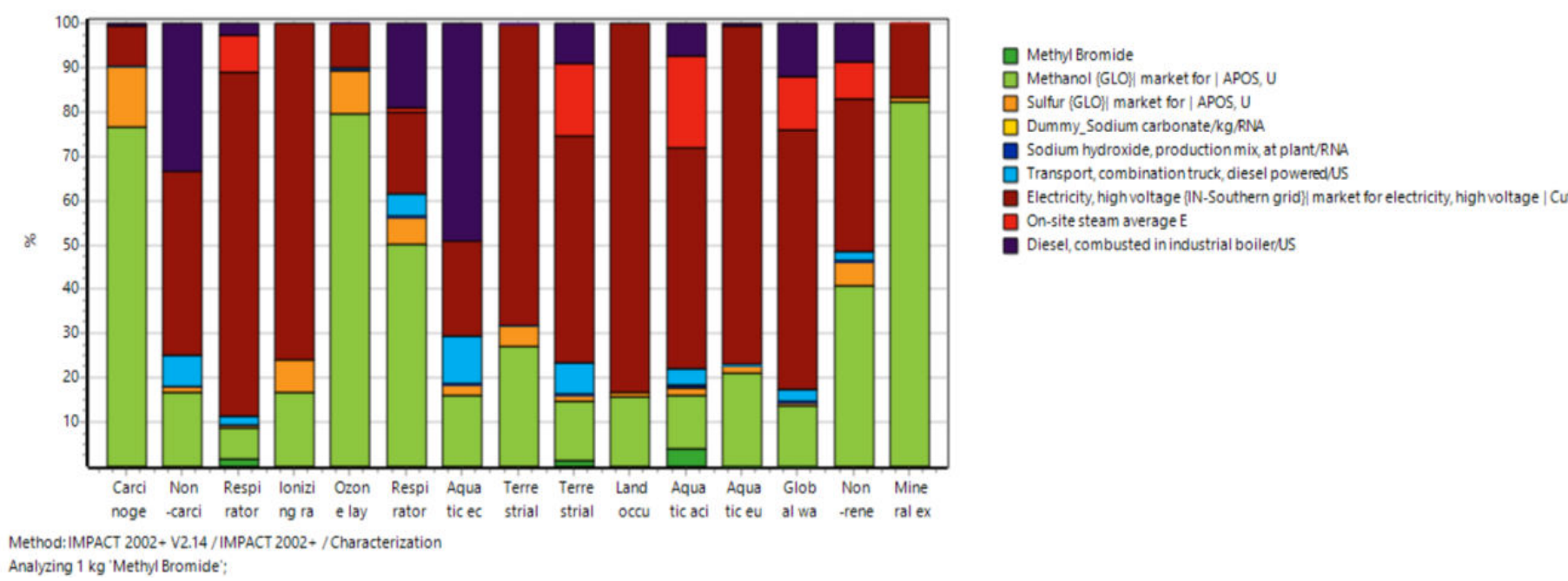

Fig.3 Characterization of emissions in MB production using the CTGT approach

In the CTGT approach, normalization and single score analysis of impact assessment results in MB production are done and are presented in Fig. 4a and Fig. 4b. The reference factor for normalization is the total impact of all substances of the specific category for which characterization factors exist, per person per year (for Europe). From Fig. $4 \mathrm{a}$ it is seen that significant impact due to various activities during MB production is on respiratory inorganics, non-renewable energy, and global warming. In a single score, analysis calculations are made on endpoint categories. From Fig. $4 \mathrm{~b}$ it is observed that electricity usage and methanol production are primary processes that cause the impact on the above-said categories. It is to be noted that in this study, methanol production is from natural gas, which is called the greener route (Chen et al. 2019). Despite the use of greener route, the environmental impacts are more due to the methanol production process as compared to other processes. If methanol production is done using coal or coke oven gas, the environmental impacts will further increase. On-site steam production and diesel combustion in boilers also affect the said categories. 


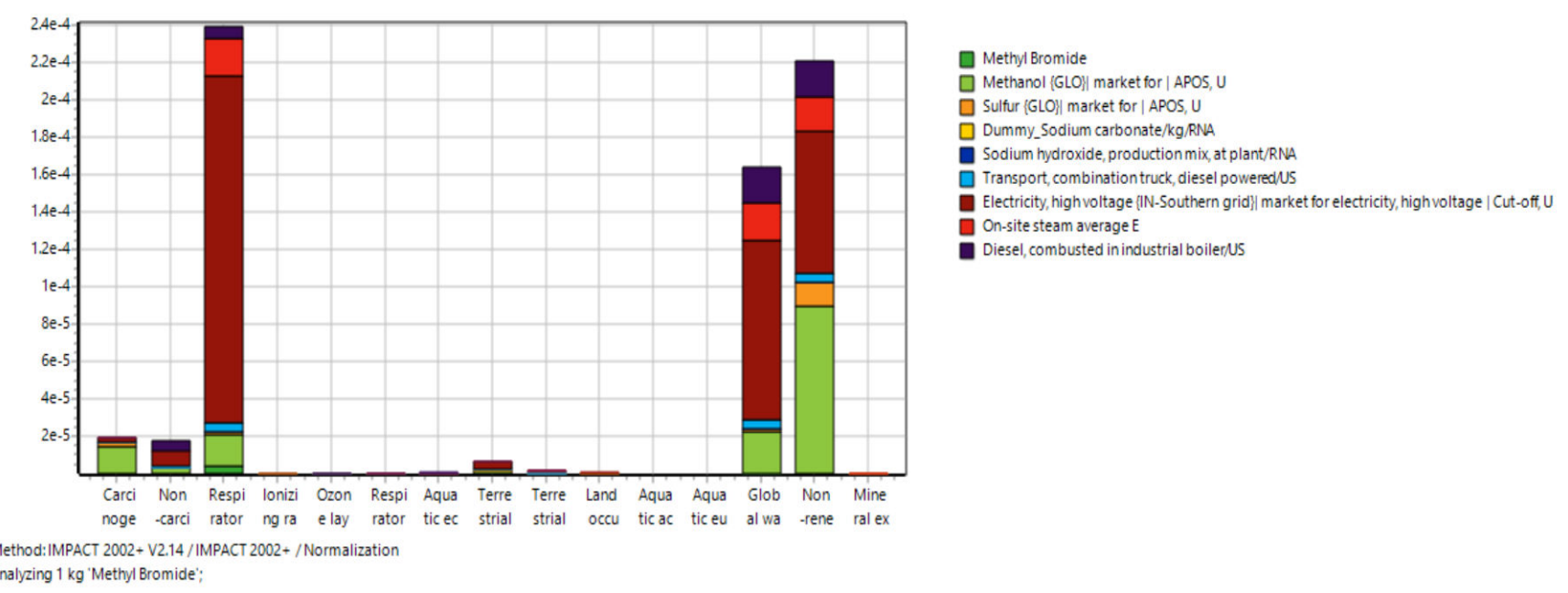

Fig.4a Normalization of impact assessment results of MB production in the CTGT approach

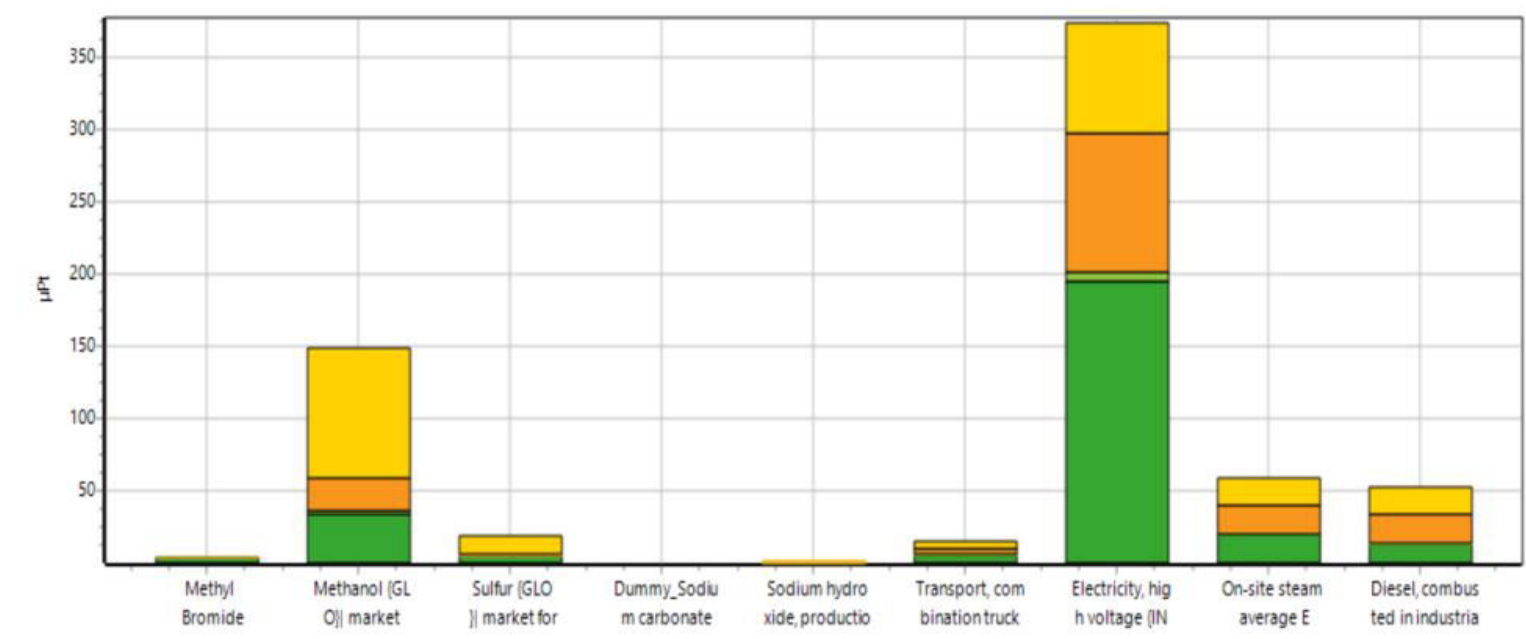

Method: IMPACT 2002 + V2.14 / IMPACT 2002 + / Single score

Analyzing $1 \mathrm{~kg}$ 'Methyl Bromide;

Fig.4bSingle score analysis of emissions from MB production in the CTGT approach

\subsection{Cradle to grave approach}

In the CTGR approach, all the stages in MB production starting from production processes of raw materials, transportation of raw materials, the onsite production process of $\mathrm{MB}$, transportation of $\mathrm{MB}$, application of $\mathrm{MB}$, and recycle of containers used for handling of $\mathrm{MB}$ are considered. This approach is a combination of CTGT and gate to grave approaches. 
Transport of MB is considered through roadways by using diesel-powered trucks within India for $500 \mathrm{kgkm}$ per $\mathrm{kg}$ of MB. Post application, $87 \%$ of MB is considered to be emitted into the atmosphere in 7 days(Yagi et al. 1993). Steel and aluminum containers used for storage of MB are considered to be recycled.

The LCA results of MB using the CTGR approach are presented through Fig.5-6. Characterizations of emissions from the production process of MB using the CTGR approach are presented in Fig. 5. From Fig. 5 it can be noted that the application of MB impacts the ozone layer since, during the application, MB breaks into bromine ion which directly depletes the ozone layer via reactions 1 and 2 mentioned elsewhere in this article. Application of $\mathrm{MB}$ also affects impact categories such as non-carcinogens, terrestrial \&aquatic ecotoxicity, and in global warming. Transportation of MB through roadways by diesel-powered trucks is having an insignificant effect on the environment as compared to other activities. However, recycling of steel cylinders and aluminum cans of MB helps in improving the environmental conditions by reducing emissions.

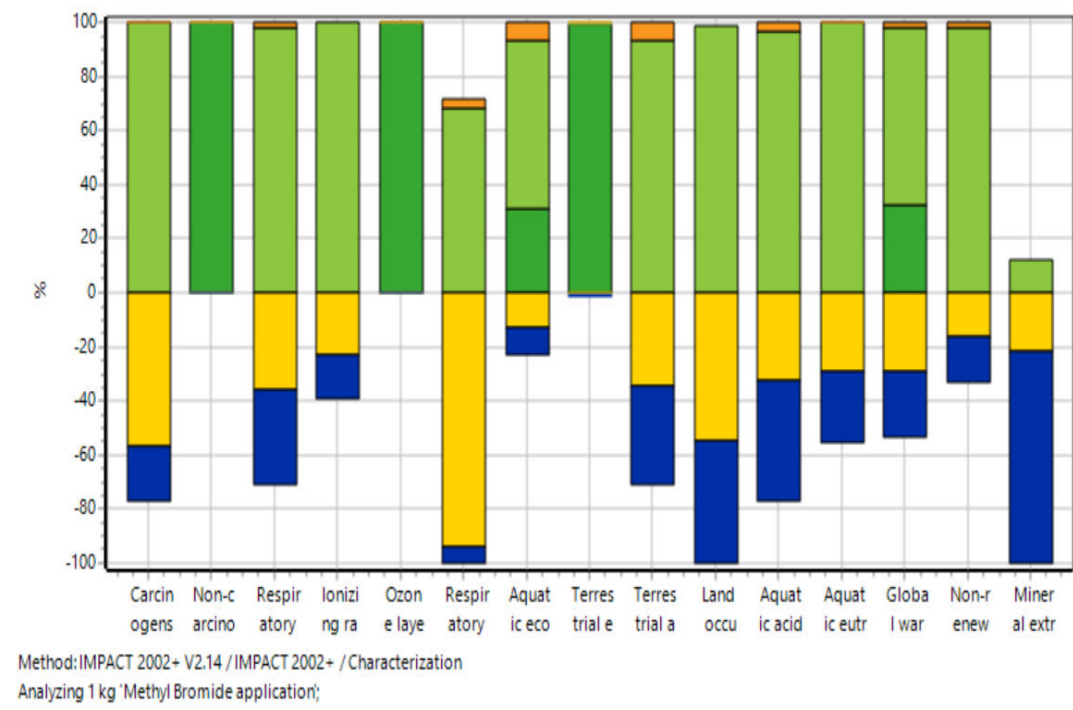

Methyl Bromide application Methyl Bromide Transport, combination truck, diesel poweredus Steel and iron (waste treatment) \{GLOY| recycling of steel and iron | APOS, U Aluminium (waste treatment) \{GLO\}| recycling of aluminium |APOS, U

Fig.5 Characterization of emissions from MB production in the CTGR approach

Normalization and single score analysis of impact assessment results of MB using the CTGR approach are presented in Fig. 6a and Fig. 6b. From Fig. 6a, it is noted that among the impact categories affected due to MB production, the ozone layer is most the most affected impact category followed by noncarcinogen. This is primarily in the MB application stage as seen from Fig. 6b. In the case of single score analysis, human health is significantly affected endpoint category. 


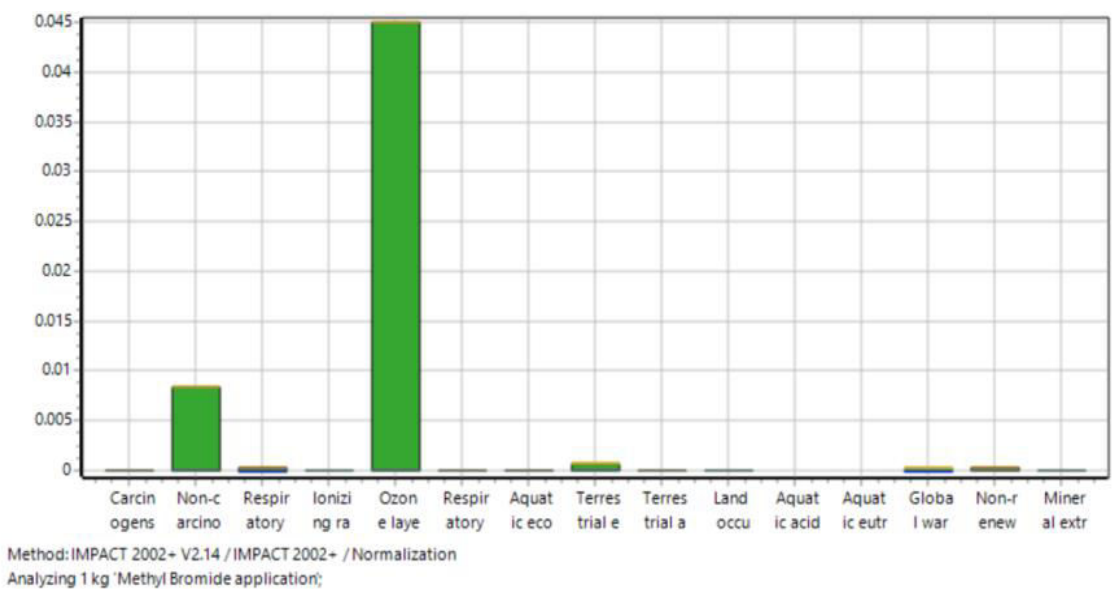

Fig.6aNormalization of impact assessment results of MB using the CTGR approach

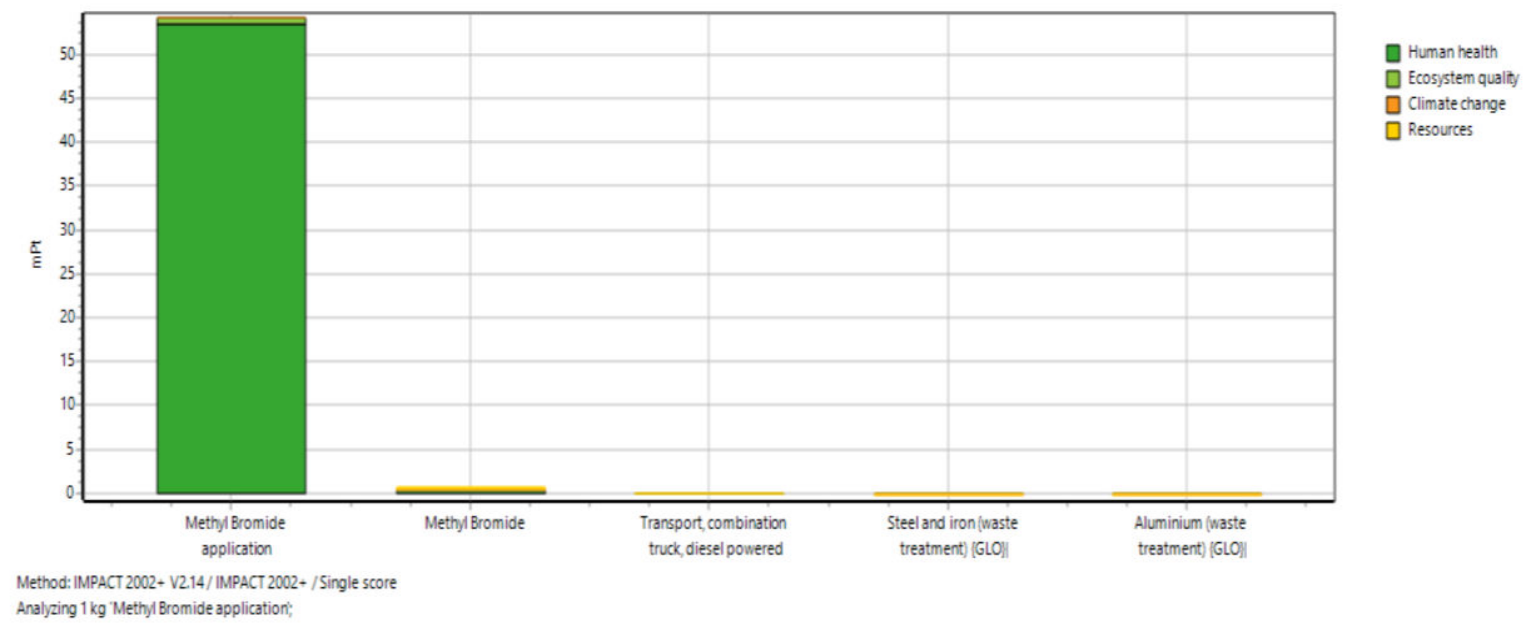

Fig.6b Single score analysis of impact assessment results of MB using the CTGR approach

\section{Conclusions}

Assessment of environmental impacts associated with MB manufactured at Intech Organics Ltd, Dhargal, Pernem, Goa, India is ascertained. Two approaches viz. CTGT and CTGR are considered for the said study. With an increase in the boundary of the process, the complexity of LCA analysis is also increased. With an increase in system boundary of LCA study, the contribution of various stages of MB's life cycle, in environmental impact are also varied.

From results and discussion of CTGT study, it is revealed that usage of the plant utilities and methanol production (one of the raw materials for production of $\mathrm{MB}$ ) are primary processes which cause the notable impact on respiratory inorganics, non-renewable energy, and global warming compared to other 
stages in LCA of MB. It is important to note that in this study, methanol production is considered to be from natural gas, which is called the greener route. Despite this, the environmental impacts are more due to the methanol production process as compared to other processes. From results and discussion of CTGR study it is revealed with the expansion of system boundary, the stages in LCA of MB, which affect the environment, are also changed. Application of MB significantly impacts the ozone layer, since, during the application, MB breaks into bromine ion which directly depletes the ozone layer. However, recycling of steel cylinders and aluminum cans of MB helps in resource conservation and also a reduction in environmental impact.

The environmental impact due to onsite usage of plant utilities can be significantly reduced by substituting conventional fuels with environment-friendly fuels and the use of non-conventional energy. Because of significant negative impact on the environment during $\mathrm{MB}$ application, it is recommended that alternative fumigants such as phosphine, sulphuryl fluoride, carbonyl sulfide, ethyl formate, ozone, hydrogen cyanide, carbon disulfide, mono-terpenes from plants or non-chemical alternatives like irradiation along with atmosphere control using nitrogen and carbon dioxide, heat and cold can be used.

\section{References}

1. Agency for Toxic Substances and Disease Registry (ATSDR)(1992). Toxicological Profile for Methyl Bromide. U.S. Public Health Service, U.S. Department of Health and Human Services, Atlanta, GA. https://www.atsdr.cdc.gov/ToxProfiles/TP.asp?id=822\&tid=160 Accessed 24 January 2020

2. ATSDR's Toxicological Profiles on CD-ROM [CD-ROM](1997). Agency for Toxic Substances and Disease Registry, U.S. Public Health Service. CRC: Boca Raton, FL, 1997. https://www.atsdr.cdc.gov/substances/toxsubstance.asp?toxid=160Accessed 24 January 2020

3. Budavari S (1989). The Merck Index. An Encyclopedia of Chemicals, Drugs, and Biologicals. 11th ed. Merck and Co. Inc., Rahway, NJ.

4. Butler JH, Rodriguez JM(1996). Methyl Bromide in the Atmosphere. In The Methyl BromideIssue; Bell, C. H., Price, N., Chakrabarti, B., Eds.; Wiley: West Sussex, England, Vol. 1, pp 27-90.

5. Chen Z, Shen Q, Sun N, Wei W(2019). Life Cycle Assessment of Typical Methanol Production Routes: the Environmental Impacts Analysis and Power Optimization. Journal of Cleaner Production. doi:10.1016/j.jclepro.2019.02.101

6. Curran MA (1996). Environmental Life Cycle Assessment. ISBN 0-07-015063-X, McGraw-Hill, New York. 
7. Curran MA (2013). Life Cycle Assessment: A review of the methodology and its application to sustainability. Curr Opin Chem Eng; 2(3): 273-77.

8. Environmental Protection Agency (EPA), Basic Ozone layer science. https://www.epa.gov/ozonelayer-protection/basic-ozone-layer-science Accessed on 20 December 2019

9. Environmental Protection Agency (EPA) (2006). Life Cycle Assessment: Principles and Practice EPA/600/R-06/060 by Scientific Applications International Corporation (SAIC).https://nepis.epa.gov/Exe/ZyNET.exe/ Accessed on 24 January 2020

10. European Commission - Joint Research Centre - Institute for Environment and Sustainability: International Reference Life Cycle Data System (ILCD) Handbook - General guide for Life Cycle Assessment - Detailed guidance. First edition March (2010) EUR 24708 EN. Luxembourg. Publications Office of the European Union; 2010. https://eplca.jrc.ec.europa.eu/uploads/ILCDHandbook-General-guide-for-LCA-DETAILED-GUIDANCE-12March2010-ISBN-fin-v1.0EN.pdfAccessed 24 January 2020.

11. Junli Shi, Zhichao Liu, Hongchao Zhang, Qiuhong Jiang and Tao Li(2015). Life Cycle Assessment: State of the Art and Future Perspectives, Recent Patents on Mechanical Engineering 2015, 8, 211 221.

12. Howard PH (1989). Methyl Bromide. In Handbook of Environmental Fate and Exposure Data for Organic Chemicals; Howard, P.H., Ed.; Lewis: Chelsea, MI, 1989; Vol 1, pp 386-393. https://nepis.epa.gov/Exe/ZyNET.exe/Accessed on 24 January 2020

13. Indiana Department of Environmental Management (IDEM), Methyl Bromide. https://www.in.gov/idem/toxic/files/studies_toxwatch_methyl_bromide.pdfAccessed 24 January 2020

14. ISO (2006a) ISO 14040-2006: International standards: environmental management - life cycle assessment-principles and frameworks. ISO, Geneva.https://www.iso.org/standard/37456.html Accessed on 24 January 2020

15. ISO (2006b) ISO 14044-2006: International standards: environmental management - life cycle assessment - requirements and guidelines. ISO, Geneva. https://www.iso.org/standard/37456.html Accessed on 24 January 2020

16. Jacobson MZ(2005). Fundamentals of Atmospheric Modeling, Cambridge University, UK.

17. Jolliet O, Margni M, Charles R, Humbert S, Payet J, Rebitzer G, Rosenbaum R. 2003. IMPACT 2002+: a new life cycle impact assessment methodology. Int. J. LCA, 8, pp. 324-330

18. MacDonald OC, Reichmuth C(1996). Effects on Target Organisms. In The Methyl BromideIssue; Bell, C. H., Price, N., Chakrabarti, B., Eds.; Wiley: West Sussex, England, Vol. 1, pp 149-189.

$\begin{array}{llll}\text { 19. MAF Biosecurity } & \text { (2009)Methyl }\end{array}$ Bromideinformationhttps://www.biosecurity.govt.nz/dmsdocument/14869/directAccessed 24 January 2020

20. National Toxicology Program (1992). Toxicology and Carcinogenesis Studies of Methyl Bromide(CAS No. 74-83- 9) in B6C3F1 Mice (Inhalation Studies). Technical Report No. TR-385. 
https://ntp.niehs.nih.gov/ntp/htdocs/lt_rpts/tr385.pdf?utm_source=direct\&utm_medium=prod\&utm campaign=ntpgolinks\&utm term=tr385 Accessed 24 January 2020

21. Oettingen WFV(1955). The halogenated aliphatic, olefinic, cyclic, aromatic, and aliphatic-aromatic hydrocarbons: Including the halogenated insecticides; their toxicity and potential dangers. U. S. Dept. of Health, Education, and Welfare, Public Health Service Publ. No. 414

22. Philip A, Sebastian K(2010). Environmental analysis of pallets using life cycle analysis and multiobjective dynamic programming. Master Thesis, Penn State, Pennsylvania. https://etda.libraries.psu.edu/catalog/11437 Accessed 24 January 2020

23. Piccirillo, VJ, Piccirillo, AL (2010). Chapter 105: Methyl Bromide. In: Krieger, R (ed) Hayes' Handbook of Pesticide Toxicology, Vol. 1, 3rd ed. USA: Academic Press, pp. 2267-2279

24. Protection of Stratospheric Ozone: Incorporation of Montreal Protocol Adjustment for a 1999 Interim Reduction in Class I, Group IV Controlled Substances. Fed. Regist. 64 (104), 29240-29245.

25. Shahidi (2011). Comparison of the potential environmental impacts of microwave phytosanitary treatment of wooden pallets to conventional heat and Methyl Bromidetreatments. Master of Science, Thesis, Pennsylvania State University. https://pdfs.semanticscholar.org/fcde/0fee974b60d56694890da51c6aeb9a5a4b6b.pdfAccessed 24 January 2020

26. Shorter JH, Kolb CE, Crill PM, Kerwin RA, Talbot RW, Hines ME, Harriss RC(1995). Rapid degradation of atmospheric Methyl Bromidein soils. Nature, 377, 717-719.

27. Sittig M(1985). M. Sittig's Handbook of Toxic and Hazardous Chemicals and Carcinogens. 2nd ed. Noyes Publications, Park Ridge, NJ.

28. United Nations Environment Programme (UNEP) 2018, Report of the Methyl Bromide Technical Options Committee 2018 Assessment. https://ozone.unep.org/sites/default/files/2019-04/MBTOCassessment-report-2018_1.pdf. Accessed on 23 July 2020.

29. U. S. Environmental Protection Agency (U.S. EPA)(1992).Methyl Bromide(bromomethane) https://www.epa.gov/sites/production/files/2016-09/documents/methyl-bromide.pdf Accessed 24 January 2020

30. U.S. Environmental Protection Agency (U.S. EPA)(1987). Health Effects Assessment for Methyl Bromide. EPA/600/8-88/022.Environmental Criteria and Assessment Office, Office of Health and Environmental Assessment, Office of Research and Development, Cincinnati, OH. https://cfpub.epa.gov/si/si_public record Report.cfm?Lab=NCEA\&dirEntryID=48366Accessed 24 January 2020

31. U.S. Environmental Protection Agency (U.S. EPA), Integrated Risk Information System (IRIS) (1999). Methyl Bromide. National Centre for Environmental Assessment, Office of Research and Development, Washington, DC.https://www.epa.gov/iris Accessed 24 January 2020

32. U.S. Environmental Protection Agency (U.S. EPA) (1986). Pesticide Fact Sheet Number 98: Methyl Bromide., Office of Pesticide Programs, U.S. Government Printing Office: Washington, DC.https://nepis.epa.gov/Exe/ZyNET.exe/Accessed on 24 January 2020 
33. Vashkov VI, Sukhova MN, Kerbabaev EB, Shnaider EV(1969). Insecticide and their application in medical practice. The United States. Air Force. Systems Command. Foreign Technology Division, 346.

34. Vaughan-Dellarco V, Fowle J, Rosenthal S(1985). Assessment of the Mutagenic Potential of Carbon Disulfide, Carbon Tetrachloride, Dichloromethane, Ethylene Dichloride, and Methyl Bromide: A Comparative Analysis in Relation to Ethylene Dibromide. U.S. Environmental Protection Agency, Washington, $\quad$ D.C., $\quad$ EPA/600/6-85/001 $\quad$ (NTIS https://cfpub.epa.gov/si/si_public_record_report.cfm?Lab=NCEA\&dirEntryId=50683 Accessed 24 January 2020

35. Watrous RM(1942).Methyl Bromide: Local and mild systemic toxic effects. Ind.Med11 (12): 575.

36. World Health Organization (WHO)(1995).Methyl Bromide, Environmental Health Criteria, 166. Geneva, Switzerland. http://www.inchem.org/documents/ehc/ehc/ehc166.htm Accessed 24 January 2020

37. Yagi I, Williams J, Wang N-Y, Cicerone RJ(1993). Agricultural Soil Fumigations as a Source of Atmospheric Methyl Bromide. Proc. Natl. Acad. Sci. U.S.A., 90, 8420-8423 


\section{Declarations}

Availability of data and material (data transparency)

All the relevant data is included in the manuscript

Conflicts of interest/Competing interests (include appropriate disclosures)

The authors declare that there is no conflict of interest and any competing interest.

Funding (information that explains whether and by whom the research was supported)

Not applicable

Authors' contributions (optional: please review the submission guidelines from the journal whether statements are mandatory)

Both the authors are involved in data collection, methodology and writing result \& discussion. It is a combined effort

\section{Acknowledgements}

The authors are thankful to Goa Pollution Control Board for providing all the necessary data to complete this project Authors acknowledge support from management of BITS Pilani K K Birla Goa campus during this project. 
